Artigo recebido em:

11.09.2016

Aprovado em:

03.05.2017

Fernanda Nalon Sanglard

Jornalista, mestre em comunicação pela UFJF (Universidade Federal de Juiz de Fora), doutora em comunicação pela Uerj (Universidade do Estado do Rio de Janeiro) e pesquisadora em comunicação e política.

E-mail: nandanalon@ yahoo.com.br.

Teresa Cristina da Costa Neves

Mestre em Comunicação pela UFRJ (Universidade Federal do Rio de Janeiro) e Doutora em Letras: Estudos Literários pela UFJF (Universidade Federal de Juiz de Fora). Professora do Programa de Pós-Graduação em Comunicação da Facom -UFJF.

E-mail: teneves@terra. com.br.

Estudos em Jornalismo e Mídia Vol. 14 No 1 Janeiro a Junho de 2017 ISSNe 1984-6924

\section{Memória, esquecimento e a (res)significação da ditadura pela CNV e pela imprensa}

\author{
Fernanda Nalon Sanglard \\ Teresa Cristina da Costa Neves
}

\section{Resumo}

O artigo reflete sobre a revisão de um trauma histórico brasileiro: a ditadura militar. Tendo como perspectiva o campo da comunicação e como respaldo teórico as discussões sobre memória e esquecimento, toma-se como ponto de partida da análise uma política pública recente: a Comissão Nacional da Verdade (CNV). Instituída em 2012 para investigar os casos graves de violações de direitos humanos ocorridos especialmente no período da ditadura militar, a CNV encerrou seus trabalhos em dezembro de 2014, com a divulgação de um relatório. Por meio da Análise de Conteúdo, investiga-se as conclusões e recomendações desse documento e também 82 relatos sobre o episódio, publicados nos veículos do mainstream (como Folha de S. Paulo, G1, Jornal Nacional, O Estado de S. Paulo e O Globo) entre os dias 10 e 12 de dezembro de 2014 . O objetivo é questionar as (res)significações da ditadura na contemporaneidade.

Palavras-Chave: Comunicação. Memória. Comissão Nacional da Verdade.

\begin{abstract}
The article reflects on the revision of a Brazilian historical trauma: the military dictatorship. With the perspective of the field of communication and theoretical support for discussions about memory and forgetfulness, a recent public policy is taken as the starting point of the analysis: the National Truth Commission (CNV). Established in 2012 to investigate serious cases of human rights violations that occurred especially during the period of the military dictatorship, the CNV ended its work in December 2014 with the release of a report. Through the Content Analysis, we investigate the conclusions and recommendations of this document and also 82 reports about the episode, published in mainstream vehicles (such as Folha de S. Paulo, G1, Jornal Nacional, O Estado de S. Paulo and O Globo) between December 10 and 12, 2014. The objective is to question the (re) significances of the dictatorship in contemporary times.
\end{abstract}

Keywords: Communications. Memory. National Truth Commission. 


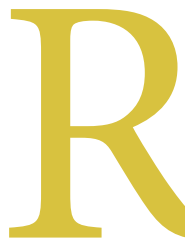

evisar traumas históricos, desenvolver novas narrativas sobre eles e propor ações que façam a sociedade repensar memórias dominantes são ações promovidas por meio de iniciativas e políticas públicas em diversas partes do mundo, entre elas as comissões da verdade criadas em mais de 40 países desde a década de 1970, sendo 21 delas compostas na primeira década do século XXI. "Essas 21 comissões mais recentes abrangem todas as regiões do mundo e uma grande variedade de contextos políticos", constata Priscilla Hayner (2011).

A Comissão de Investigação sobre o Desaparecimento de Pessoas, estabelecida em 1974 pelo governo de Uganda, na África, é reconhecida como a primeira ação de uma comissão da verdade, ainda que não tenha recebido oficialmente este nome. O objetivo era investigar as acusações de desaparecimentos praticados pelas forças militares durante os primeiros anos do governo de Idi Amin Dada, o mesmo que criou a comissão. Anos mais tarde, iniciativas do tipo começam a se espalhar por outros continentes.

Segundo Hayner (2011), apesar de o pioneirismo ser de Uganda, a primeira comissão da verdade amplamente conhecida foi a da Argentina, criada em 1983. O órgão também não era referenciado como uma comissão da verdade naquela época, sendo chamado de Comissão Nacional de Desaparecidos (Conadep). A autora registra que o título "comissão da verdade" surgiu quase dez anos mais tarde, com a Comissão Nacional de Verdade e Reconciliação do Chile e a Comissão da Verdade de El Salvador, concluídas em 1990 e 1992, respectivamente. (HAYNER, 2011).

Criada pela Lei 12.528/11 e instituída apenas em 2012, a Comissão Nacional da Verdade (CNV) - nome recebido pelo órgão no Brasil - recebeu a incumbêmcia de apurar os casos de violações dos direitos humanos ocorridos entre 1946 e 1988 (período entre as duas Assembleias Constituintes), o que inclui a ditadura militar. Inicialmente, a $\mathrm{CNV}$ teria exatos dois anos de atuação, mas o prazo foi prorrogado e a comissão passou a ter até o fim de 2014 para concluir o relatório, totalizando dois anos e sete meses de trabalho. A partir do recolhimento de depoimentos orais, visitas a instalações usadas pela repressão e de pesquisas realizadas em arquivos - muitos deles até então fechados para consultas -, o grupo de trabalho pretendeu promover a responsabilização não-penal pelos crimes ocorridos durante o regime de exceção e contribuir para a divulgação de fatos ainda obscuros.

De acordo com o livro-documento Direito à Memória e à Verdade, elaborado pelo governo federal, há 150 casos de opositores do regime militar que desapareceram após serem presos ou sequestrados por agentes do Estado. Não há registro da prisão deles em nenhum tribunal ou presídio, os advogados não foram notificados e os familiares até hoje procuram esclarecimentos sobre onde estão os corpos das vítimas. Em 2010, o Brasil foi condenado na Corte Interamericana de Direitos Humanos da OEA em ação movida por familiares de mortos e desaparecidos na Guerrilha do Araguaia [...] (COMISSÃO NACIONAL DA VERDADE, 2012).

Conforme Hayner, é justamente a ação de órgãos internacionais em prol dos direitos humanos que tem cobrado e motivado o desenvolvimento de muitas comissões da verdade pelo mundo. Investigar e tornar públicas as violações dos direitos humanos cometidas no passado por agentes de Estado começou a ser algo interpretado pelas cortes internacionais como obrigação dos países. Tal procedimento tem sido reafirmado por documentos e resoluções voltadas para políticas públicas.

Relatório aprovado pela Comissão das Nações Unidas sobre Direitos Humanos afirma o direito inalienável de se conhecer a verdade sobre os aconte- 
cimentos passados e de que as vítimas e suas famílias sejam informadas sobre as circunstâncias em que ocorreram as violações.

Enquanto o relatório observa que as sociedades podem se beneficiar de uma comissão da verdade, ele deixa claro que qualquer decisão de criar tal comissão, ou para definir seus termos e composição, "deve ser baseada em amplas consultas públicas em que os pontos de vista das vítimas e sobreviventes especialmente são procurados" (HAYNER, 2011, p. 24, tradução nossa).

Para estudiosos dos processos de justiça de transição, como Freeman (2006) e Hayner (2011), comissões da verdade surgem - ou ao menos deveriam surgir - como órgãos temporários destinados a mudar políticas e práticas a partir de investigação sobre um padrão de acontecimentos (violência e repressão) ocorridos em determinado período, sendo oficialmente autorizadas ou habilitadas pelo Estado. A partir desse entendimento, tais comissões se tornaram iniciativas importantes para estimular a sociedade a lidar com memórias que não ganhavam espaço no debate público, responsabilizando violadores, reparando vítimas, propondo reformas e estimulando manifestações sociais, políticas e artísticas.

Sob este ponto de vista, comissões da verdade são provocadoras do debate público e também responsáveis pelo (re) ingresso da temática dos grandes traumas na mídia e, consequentemente, na arena pública. São, portanto, iniciativas de interesse do campo da comunicação, no sentido de que estimulam novas narrativas, representações e (res)significações - seja no jornalismo, seja no cinema, ou ainda em outras formas de manifestações culturais de alcance popular - sobre os fenômenos investigados. Parte-se do entendimento de que o campo da comunicação é algo mais amplo que o espaço teórico preocupado apenas com a transmissão das informações ou com os estudos de mídia. Defende-se neste artigo que o âmbito das práticas comunicacionais compõe-se como objeto de investigação vinculado ao que se desenvolve em comunidade e se relaciona com a capacidade de convivência e partilha, ou seja, com o ato de comunicar, incluindo aí as políticas que visam instituir novas narrativas e formas de comunhão social. Comissões da verdade podem ser, portanto, consideradas ferramentas de comunicação e mobilização política. Todavia, a relevância de sua repercussão nos espaços midiáticos não pode ser menosprezada.

Desta perspectiva, pretende-se analisar a conclusão e as recomendações reunidas no Capítulo 18 do relatório final da CNV, buscando-se distinguir estas proposições como gestos comunicacionais que, revisando as relações entre memória e esquecimento, objetivam ampliar informações, (re)compor sentidos e enriquecer repertórios acerca da ditadura militar brasileira. É especificamente nesses trechos do documento que a comissão não só manifesta de modo explícito sua intenção de propor outros significados acerca do período ditatorial, mas também assume uma postura pragmática, sugerindo a adoção de políticas públicas baseadas nos esclarecimentos e desvelamentos resultantes de seu trabalho. As inferências extraídas desse exame serão cotejadas com os resultados da análise de conteúdo da cobertura noticiosa da divulgação do relatório.

Serão testadas três hipóteses: (1) o jornalismo brasileiro, ao menos naquele momento, garantiu extensa cobertura à CNV e ao relatório, (2) tal cobertura destaca os aspectos mais polêmicos do relatório, (3) mas o enquadramento episódico do fato é privilegiado, não havendo grande investimento no aprofundamento das discussões acerca do impacto político e social do relatório.

A investigação do conteúdo jornalístico objetiva identificar os enquadramentos privilegiados para compreender como a imprensa brasileira se comportou quanto à divulgação do relatório fi- 
nal no dia de seu lançamento e nos dois dias subsequentes, considerando-se que esta forma de manifestação midiática concorre para a composição de significados coletivamente partilhados. São analisados 82 relatos divulgados entre $10 \mathrm{e}$ 12 de dezembro de 2014 em veículos do mainstream (como Estado de São Paulo, Folha de S. Paulo, G1, Jornal Nacional e O Globo).

\section{Os dilemas entre lembrar e esquecer}

Focada na cobertura do desfecho dos trabalhos da CNV, a análise do conteúdo noticioso é relevante para verificar os enquadramentos privilegiados pela mídia, porém insuficiente para compreendê-los frente aos enfoques utilizados pela própria comissão. Desse modo, um entendimento mais preciso da divulgação feita pela imprensa requer investigação minuciosa do texto original entregue pela comissão, buscando-se refletir sobre as articulações que resultaram nas angulações adotadas pelos veículos.

A avaliação crítica do trecho conclusivo do relatório procede de uma problematização do conceito de memória a partir de perspectivas distintas, como as da história, da filosofia e da psicanálise. Esse quadro teórico tem como um de seus expoentes Henri Bergson (2006) e a diferenciação que propõe entre lembrança e duração. De acordo com o autor, passado e presente coexistem no que ele chama de duração (durée, em francês), que designa o tempo real, o tempo vivido, temporalidade na qual percebemos a nossa existência. $\mathrm{O}$ autor distingue a durée do tempo cronológico, aquele que consiste em uma sucessão de acontecimentos.

Você define arbitrariamente o presente como o que existe, quando o presente é simplesmente o que se faz. Nada existe menos que o momento presente, se entender por isso esse limite indivisível que separa o passado do porvir. Quando pensamos esse presente devendo existir, ele ainda não existe; e, quan- do o pensamos quando existente, ele já passou. Se, ao contrário, você pensar o presente concreto e realmente vivido pela consciência, pode-se dizer que esse presente consiste em grande parte no passado imediato (BERGSON, 2006, p. 90).

Para Bergson, a maneira de o passado sobreviver na duração é a memória. Portanto, o passado nunca deixa de existir, apenas deixa de ser útil. Já a lembrança é uma virtualidade, ou seja, algo potencial. Assim, Bergson diferencia a memória hábito da memória lembrança. Segundo ele, ao automatizarmos gestos e comportamentos, não precisamos ficar nos lembrando de como realizá-los diariamente, o que implica que fazemos uso da memória hábito, a mera atualização da repetição (andar, escrever, segurar o garfo para comer etc.). Já a memória lembrança seria a "verdadeira memória”. Para que algo novo entre na nossa memória lembrança, precisamos estranhá-lo, experimentá-lo como novidade, abrindo espaço para o que não é mecânico, rotineiro.

Conforme o filósofo francês, a armadilha de se acomodar à memória hábito desestimula a percepção, faculdade sempre impregnada de lembranças.

Em suma, perceber consiste em condensar períodos enormes de uma existência infinitamente diluída em alguns momentos mais diferenciados de uma vida mais intensa, e em resumir assim uma história muito longa. Perceber significa imobilizar (BERGSON, 2006, p. 88).

A dificuldade das políticas de memória está, justamente, em definir o que deve ser "imobilizado", ou melhor, o que será lembrado e o que provavelmente ficará ou deve permanecer esquecido. A ameaça deste impasse leva Huyssen (2014, p.160) a defender o esquecimento público, em determinadas situações históricas, de modo a se constituir num "discurso politicamente desejável da me- 
mória”. Nem sempre é fácil ou possível fazer escolhas racionais e viáveis, adverte Huyssen, pois legislar sobre esquecimento público pode se revelar tão inútil quanto preceituar maneiras "corretas" de se lembrar.

No caso brasileiro, a Lei da Anistia serve de ilustração da impropriedade de esquecimentos públicos apressados e irrefletidos, que em muitos aspectos reiteram e reforçam aquilo mesmo que se propõem a deixar para trás.

Em sua reflexão acerca do recurso à anistia como estratégia política, a historiadora francesa Nicole Loraux (2008) resgata as origens do termo na Atenas do século $\mathrm{V}$ a.C., aí localizando a constituição de dois episódios paradigmáticos para a composição de um "estatuto da memória cívica". Naquele remoto contexto, uma interdição (referente à representação de um episódio trágico da história grega) e uma promessa (relativa a um gesto de reconciliação interna posterior a uma guerra civil) recobriram o termo de um duplo sentido: o de prescrição ("proibição de recordar as desgraças") e o de juramento ("não recordarei as desgraças"). Seja pela decretação do esquecimento, seja pelo compromisso de não lembrar, o gesto de negar a memória trai a percepção dos atenienses quanto aos perigos da rememoração e dos sentimentos hostis de represália por ela despertados.

A compreensão de que "a política seria o que começa onde termina a vingança" assumiu contornos semânticos de "sabedoria" ou "lição aprendida" com as desgraças antecedentes. Por esta linha de pensamento, o bom político é o que age com moderação, assumindo postura conciliatória, como se os infortúnios não houvessem acontecido: "nem o conflito, nem o crime, nem o ressentimento (ou o rancor)" (LORAUX, 2008, p. 153, tradução nossa). Entretanto, pondera a autora, os males são como cicatrizes, marcas que não se pode esquecer. $\mathrm{O}$ que se decreta ou se jura esquecer em nome da harmonia não se pode conciliar com a memória da "dor inesquecível". É assim que anistia, segundo Loraux, assume o significa- do de esquecimento do inesquecido em prol da coletividade:

$\mathrm{Na}$ ordem de "não recordar as desgraças", veremos, pois, menos uma forma de esquecer os males (lethe kakôn), em sua inquietante doçura, que uma maneira de anular, evitando toda referência explícita ao esquecimento, esse oximoro nunca formulado que se oculta sob o "esquecimento dos males", isto é, o esquecimento do não-esquecido (LORAUX, 2008, p. 158, tradução nossa).

Indo além da concepção originária de anistia, conforme concebida em Atenas, autores como Freud (1996) e Ricour (2007) desenham um quadro mais complexo. A partir do alvorecer do século XX começa a prevalecer a ideia de que o sobrepujamento de uma "dor inesquecível", um "recalque" ou um "trauma" é incompatível com a persistência de "memórias obrigadas" ou "esquecimentos forçados". Segundo tal perspectiva, só um "trabalho de memória" e uma vivência do "luto" facultam a superação do passado e sua reconfiguração no presente e no futuro. As concepções de esquecimento e perdão se aproximam do sentimento de justiça.

As tensões resultantes do controverso "pacto da anistia" no Brasil são exemplares a esse respeito e transparecem nos discursos de caráter conciliatório acerca da ditadura militar em espaços midiáticos de ampla repercussão nacional. Embora as novas políticas de memória brasileiras tentem suplantar antigas "prescrições", ainda se revelam impotentes para vencer os entraves decorrentes de uma interpretação da lei de anistia dissonante do que é postulado pelas cortes internacionais das quais nosso país é signatário. A fala do ministro do Supremo Tribunal Federal Marco Aurélio Mello em entrevista concedida à Folha de S. Paulo no dia do lançamento do relatório final da CNV é sintomática das dificuldades de se determinar o que deve ser esquecido e de se fomentar políticas públicas nesse sentido. Arguido so- 
${ }^{1}$ Disponível em: <http:// www1.folha.uol.com.br/ poder/2014/12/1560301-anistia-e-perdao-em-sentido-maior-e-nao-deve-ser-revisada-diz-ministro-do-stf. shtml>. Acesso em 10 jan.

2016. bre a Lei de Anistia, ele afirmou: "Vamos consertar o Brasil para o futuro, não para o passado"'.

Podemos escolher entre querer lembrar ou querer esquecer. E, como rememorar depende de empenho, por vezes esquecer aparenta ser a escolha mais fácil. Contudo, o que se pretende demonstrar é que o esquecimento, comumente visto como nocivo ou prejudicial, constitui-se como capacidade humana complexa que pode assumir conotações positivas. Esquecer pressupõe elaborar nosso acervo de memórias, procedendo a escolhas que objetivem o "apaziguamento" de lembranças e a convivência com narrativas sobre nós mesmos e acerca do que está à nossa volta. Portanto, esquecer é bem diferente de apagar ou "deletar". Esquecer é algo necessário à sobrevivência. Mas o que devemos lembrar para conseguir esquecer?

A dicotomia entre memória e esquecimento persiste desde a mitologia grega, sendo Mnemosine a deusa da memória e Lesmosyne a representante do esquecimento. Pensadores como Sigmund Freud, na psicanálise, e Jacques Le Goff, na história, desmitificaram essa ideia binária, passando a compreender memória e esquecimento como processos de um mesmo fenômeno.

O historiador Paul Ricœur (2007, p.397) recorre ao texto História e memória, de Le Goff (1990), para tornar a memória mais do que "matéria-prima da história", já que a disciplina histórica alimenta a memória e integra o grande processo dialético da memória e do esquecimento.

Ao expor as razões pelas quais intitulou sua obra A memória, a história e o esquecimento, Ricœur (2007, p. 423) equipara o esquecimento à memória $\mathrm{e}$ à história, porém alerta: "De fato, o esquecimento continua a ser a inquietante ameaça que se delineia no plano de fundo da fenomenologia da memória e da epistemologia da história". Trata-se de uma interdependência sob constante tensão:

De início e maciçamente, é como dano à confiabilidade da memória que o esquecimento é sentido. Dano, fraqueza, lacuna. Sob esse aspecto, a própria memória se define, pelo menos numa primeira instância, como luta contra o esquecimento. Heródoto ambiciona preservar do esquecimento a glória dos gregos e dos bárbaros. E nosso famoso dever de memória enuncia-se como uma exortação a não esquecer. Porém, ao mesmo tempo, e no mesmo movimento espontâneo, afastamos o espectro de uma memória que nada esqueceria (RICEER, 2007, p. 424).

Conforme o autor, o esquecimento não pode ser visto como inimigo ou oposto da memória. Esquecimento e memória convivem como em uma relação de alteridade, afinal, só existe memória porque há esquecimento e viceversa. Mas o crítico literário e da cultura Andreas Huyssen (2014, p.157) pondera que devemos ir além da reafirmação contraditória de que o esquecimento é constitutivo da memória, porque "reconhecer esse paradoxo reconcilia-se muito facilmente com continuar a privilegiar a memória em relação ao esquecimento".

Os esforços da Comissão Nacional da Verdade, a exemplo de outras iniciativas semelhantes, empenham-se no exercício da rememoração, mas também propõem práticas de esquecimento. Conforme se pode apreender nas conclusões de seu relatório, a CNV dedica-se com afinco a comprovar graves violações dos direitos humanos, vinculando-as ao autoritarismo de um período histórico culturalmente relegado à deslembrança. Esta disposição em transmudar esquecimento em memória se traduz, no documento da comissão, em reiterada alusão às comprovações de que houve no Brasil, sobretudo entre 1964 e 1985, uma "prática sistemática de detenções ilegais e arbitrárias e de tortura, assim como o cometimento de execuções, desaparecimentos forçados e ocultação de cadáveres por agentes do Estado brasileiro" (RELATÓRIO DA CNV, 2014, p. 962). 


\section{As proposições da CNV}

Com base nas disposições legais e no resultado de suas investigações, a CNV produziu um relatório no qual dedica o Capítulo 18 às suas considerações finais e recomendações, que, em seu conjunto, podem ser tomadas como proposições para uma política nacional de memória. Devidamente repercutidos na mídia, esses preceitos equivalem a uma pauta de discussões para um debate nacional em torno das posturas adotadas em relação ao passado autoritário.

$\mathrm{Na}$ primeira parte do capítulo em questão, as conclusões são apresentadas em quatro eixos nos quais se constata que: (1) houve graves violações de direitos humanos; (2) estas foram sistemáticas; (3) caracterizam-se como crimes contra a humanidade e (4) algumas delas persistem no regime democrático. No segundo tópico, são propostas tanto "medidas institucionais" quanto "reformas constitucionais e legais".

Em benefício da rememoração de abusos, tendo em vista sua não repetição e reparação, são preconizados no relatório: a garantia pelo Estado de atendimento médico e psicossocial às vítimas de violações; o prosseguimento das buscas pelos restos mortais de desaparecidos; a preservação de imóveis que tenham abrigado práticas violadoras dos direitos humanos e a criação de um museu devotado a manter vivas tais experiências.

Em contrapartida, está incluído no documento um rol de ações e providências francamente propositivas de um exercício deliberado de esquecimento. Estão entre tais recomendações, que visam não o mero apagamento de rastros, mas a superação de vícios e injustiças herdados do regime ditatorial: a proibição de comemorações relativas ao golpe militar de 1964; a supressão de referências à doutrina de segurança nacional nos processos de formação e capacitação de efetivos das Forças Armadas e dos órgãos de segurança pública; a exclusão das vítimas de perseguição política dos bancos de registros criminais; a revo- gação da Lei de Segurança Nacional; a desmilitarização das polícias militares; a extinção dos órgãos estaduais da Justiça Militar; a retirada da legislação de referências discriminatórias da homossexualidade; a eliminação do eufemismo "auto de resistência" nos registros de lesões e mortes decorrentes de operações policiais; a substituição de nomes de logradouros e prédios públicos que homenageiam acusados de violação.

O movimento de esquecer memórias e lembrar esquecimentos proposto pela CNV está inserido num processo que nos últimos 20 anos vem constituindo, em várias partes do mundo, uma cultura memorial baseada em histórias traumáticas e discursos de vitimização, presentes nas manchetes jornalísticas e no debate popular. Autor desse diagnóstico, Huyssen define a cultura contemporânea como "obcecada" pela memória e pelo trauma, sendo o esquecimento quase sempre "malvisto". Não raro, o ato de esquecer "é descrito como uma falha da memória: clinicamente, como disfunção; socialmente, como distorção; academicamente, como uma forma de pecado original; em termos de vivência, como um subproduto lamentável do envelhecimento" (HUYSSEN, 2014, p.155).

Para o pensador alemão, o esquecimento é vítima de descaso no pensamento filosófico, o que pode ser constatado nas obras de Platão, Kant, Descartes, Heidegger, Derrida e Umberto Eco. Nem mesmo Adorno e Benjamin escapam das críticas, pois não enfocaram os fatores geradores do esquecimento. A exceção cabe a Nietzsche, a quem restou fazer a defesa de uma ética do esquecimento.

Em suas "considerações intempestivas” (ou extemporâneas), o pensador alemão faz talvez uma de suas mais importantes e originais reflexões: a de que o ser humano não pode viver sem esquecimento. Segundo ele, “[...] é possível viver quase sem lembrança, e mesmo viver feliz, como mostra o animal, mas é inteiramente impossível, sem esquecimento, simplesmente viver" (NIETZSCHE, 2003, p.274).

Ao desconstruir, por meio de afo- 
rismos, alguns dos mais sólidos paradigmas filosóficos ocidentais, Nietzsche (2003) considera que o que passou deve abrir o olhar para o futuro e critica o homem do século XIX, tão empenhado em "mumificar o passado". Sugere enfaticamente que experiências pretéritas se tornem objeto de conhecimento a ser projetado no porvir. Para ele, o passado ensina que a vida está em constante mudança e, por isso, não podemos nos prender para sempre ao que já ocorreu. Tal postura, de modo algum, se confunde com o gesto de apagar a história. $\mathrm{O}$ que Nietzsche quer dizer - e explicita em outra de suas obras, Genealogia da moral (NIETZSCHE, 2009) -, é que esquecer é um ato semelhante a digerir, pois envolve assimilação.

É preciso elaborar, (re)ler criticamente e (res)significar o vivido para lograr esquecer. Trata-se de um exercício existencial - seja individual, seja coletivo - por meio do qual convertemos em alimento para a vida algo depurado de certa vivência, enquanto nos desapegamos daquela parte de dada experiência que não nos serve para viver. Ou seja, é necessário nutrir a existência tanto com a memória quanto com o esquecimento. Segundo o pensamento nietzschiano, quem não consegue esquecer torna-se refém do ressentimento - noção equivalente às consequências psíquicas do recalque na obra de Freud -, restando impedido de agir e (se) propor (a)o novo.

Os resultados expressos pela Comissão Nacional da Verdade apontam nesta direção. As conclusões do relatório são enfáticas ao diagnosticarem certa "indigestão" que acomete a sociedade brasileira, cujo sintoma se manifesta na dificuldade em, de fato, deixar para trás o passado doloroso, uma vez que não houve decantação nem expurgo do que foi traumaticamente vivido.

Embora não ocorra mais em um contexto de repressão política como ocorreu na ditadura militar -, a prática de detenções ilegais e arbitrárias, torturas, execuções, desaparecimentos forçados e mes- mo ocultação de cadáveres não é estranha a realidade brasileira contemporânea. Relativamente a atuação dos órgãos de segurança pública, multiplicam-se, por exemplo, as denúncias de tortura [...]. Esse quadro resulta em grande parte do fato de que o cometimento de graves violações de direitos humanos verificado no passado não foi adequadamente denunciado, nem seus autores responsabilizados, criando-se as condições para sua perpetuação (RELATÓRIO DA CNV, 2014, p. 964).

O dano observado pela CNV continuidade das violações autoritárias no regime democrático e falta de enfrentamento desse problema - remete, conforme diagnosticado pelos comissários, ao fato de tais violências não terem sido adequadamente denunciadas, visto que o país carece de políticas públicas mais efetivas nesse sentido. Muitos documentos estavam ou ainda continuam desaparecidos, os suspeitos de terem cometido as violações não foram responsabilizados, nem revelaram tudo o que sabem e dezenas de famílias ainda convivem com a dor de não poder enterrar os corpos de seus parentes desaparecidos na ditadura. Isso faz crer que muito do que mereceria vir à tona permanece de algum modo encoberto por manipulações ou ideologizações da memória.

Tal ideia remete à reflexão de memória manipulada, instrumentalizada nas relações de poder e fortemente atrelada à ideia de narratividade, conforme apresentado por Ricoeur. Este conceito alude à memória prática, permitindo que versões de memória sejam construídas e esquecimentos sejam forjados, na medida em que compreende qualquer narrativa como seletiva. Esta memória manipulada também tem relação com o esquecimento público e as políticas de memória delineadas por Huyssen (2014). As manipulações de memória são processos ideológicos que alcançam expressão por meio de construções narrativas, responsáveis por forjar e modifi- 
car nossas identidades (pessoais e coletivas). Portanto, deve-se levar também em conta que a memória manipulada é sempre espaço aberto para que haja algum tipo de abuso, tanto de memória quanto de esquecimento. Assumir posição crítica é uma forma de enfrentar esse tipo de manipulação.

O ponto de vista analítico, denunciador de falsificações e encobrimentos, está no âmago de iniciativas empenhadas em desvendar a "verdade" acessível por meio do resgate e da ressignificação da memória. No trecho do relatório da CNV examinado, a intenção de denunciar manipulações e propor narrativas diferenciadas sobre o passado é onipresente, na maior parte das vezes de modo implícito, embora também se mostre explicitamente. É o que se verifica, por exemplo, na afirmação de que, baseada nos resultados de sua inquirição, a comissão "refuta integralmente [...] a explicação, que até hoje tem sido adotada pelas Forças Armadas", segundo a qual "as graves violações de direitos humanos se constituíram em alguns atos isolados ou excessos, gerados pelo voluntarismo de alguns poucos militares" (RELATÓRIO DA CNV, 2014, p. 963).

Um outro tipo de abuso a que Ricoeur se refere diz respeito à memória obrigada, aquela vista como um dever, uma obrigação, podendo ser entendida também como um esquecimento compulsório. É o que o autor chama de "dever de memória", ideia que se relaciona com a de coerção e a de justiça, frequentemente posta em prática por meio da concessão de prioridade às vítimas. Esta memória envolve então sentimento de culpa e de dívida, sendo um de seus exemplos o esquecimento institucional que prevalece nos casos de anistia ${ }^{2}$, bem como o comportamento de pessoas que buscam, com seus depoimentos a comissões da verdade ou de anistia, cumprir e cobrar certo "dever de memória", no qual estão incluídos o reconhecimento do sofrimento, seu reparo e sua indenização.

Este espírito segundo o qual a memória faculta o cumprimento do que é justo está absolutamente evidente na parte conclusiva do documento final produzido pela Comissão Nacional da Verdade. Não há rodeios para se declarar a franca intenção de privilegiar o reconhecimento das vítimas e a reparação de injustiças contra elas cometidas, condutas proteladas por décadas, tanto pelas instituições nacionais quanto pela sociedade brasileira. Em seu desfecho, o relatório da CNV denota seu intento de contrapor narrativas hegemônicas, dando voz e vez aos que foram submetidos ao peso da arbitrariedade, ao realçar o caráter oficial e inescapável das ações espúrias:

Na ditadura militar, a repressão e a eliminação de opositores políticos se converteram em políticas de Estado, concebida e implementada a partir de decisões emanadas da presidência da República e dos ministros militares. Operacionalizada através de cadeias de comando que, partindo dessas instâncias dirigentes, alcançaram os órgãos responsáveis pelas instalações e pelos procedimentos diretamente implicados nas atividades repressivas, essa política de Estado [...] se abateu sobre milhares de brasileiros (RELATÓRIO DA CNV, 2014, p. 963).

Os discursos contemporâneos sobre a memória são decisivamente influenciados por questões políticas e traumáticas que os precederam, como advertem tanto Huyssen (2014), quanto o filósofo e crítico literário George Steiner (1992), a propósito do Holocausto e de outros episódios históricos cruéis do século XX, como as ditaduras na América Latina, o apartheid na África do Sul e os genocídios da Bósnia e de Ruanda. Se a barbárie da Segunda Guerra impregnou toda a cultura que a sucedeu, maculando as produções intelectuais e artísticas que "floresceram em apertada proximidade espacial e temporal com o massacre e os campos de extermínio", é necessário examinar "a estrutura e o significado dessa proximidade", adverte
${ }^{2} \mathrm{O}$ conceito de anistia também remete ao campo semântico do perdão. Contudo, há quem questione se, de fato, as vitimas deveriam ser perdoadas, já que não teriam do que se desculpar. O Estado e os violadores são, segundo tais argumentos, os únicos que deveriam pedir perdão. 
${ }^{3}$ Chegou-se a este número a partir de material coletado no clipping da CNV nas datas mencionadas.

${ }^{4}$ Para melhor compreensão da perspectiva teórico-conceitual de enquadramento ver também Tuchman (1978), Gitlin (1980), Entman (1993), D’angelo \& Kuypers (2010).
Steiner (1992, p. 40).

O caminho interpretativo apontado pelo autor também pode ser entrevisto no trecho conclusivo do texto que relata os trabalhos da CNV. Ao embasar suas considerações finais, a comissão faz referência à designação de "crimes contra a humanidade", empregada nos tratados internacionais de direitos humanos, para definir condutas criminosas e desumanas que se consolidaram ao longo do século XX e no início do século XXI. É nessa categoria de violações que se inserem, de acordo com o relatório, os abusos perpetrados pela ditadura militar brasileira, num "quadro de violência que resultou em expressivo número de vítimas" (RELATÓRIO DA CNV, 2014, p. 963).

\section{A cobertura midiática do relatório final}

A partir de acesso ao clipping de notícias disponibilizado pela equipe de comunicação da CNV, elaboramos um banco de dados com 218 relatos noticiosos (notas, notícias, reportagens e artigos de opinião) veiculados entre 10 de dezembro de 2014 (data de divulgação oficial do relatório final) e 12 de dezembro de 2014. Deste banco de dados, optamos por trabalhar com o material proveniente do jornalismo mainstream de circulação - ou abrangência - nacional, com presença na internet e cujos links das matérias permanecem ativos. Assim, a análise restringiu-se ao conteúdo dos impressos $O$ Estado de São Paulo (Estadão), O Globo e Folha de S. Paulo, do telejornal Jornal Nacional, da Rede Globo, e do portal de notícias G1. Dessa forma, chegou-se a 82 unidades de análise (registros noticiosos) que podem ser consideradas espectro suficiente para compreender como a grande mídia atuou diante de tal cobertura.

É necessário mencionar o destaque que a imprensa garantiu aos temas relativos à ditadura e à CNV no período em questão, já que as 218 notícias se referem a apenas três dias de cobertura, demonstrando que, quantitativamente, a comissão atingiu o objetivo de se fazer notória e de levar as revisões sobre a ditadura ao grande público.

As 82 unidades que compõem o corpus da pesquisa foram organizadas por data de publicação, veículo, editoria, título, link da matéria. Posteriormente, verificou-se a frequência do conteúdo no noticiário por veículo, o que resultou nos seguintes dados: o jornal Folha de S. Paulo foi o que mais noticiou o tema nos dias em questão, sendo responsável por 35 matérias $(42,7 \%)$; já $O$ Globo publicou 23 (28\%); Estadão, 12 (14,6\%); G1, $10(12,2 \%)$ e Jornal Nacional, uma reportagem e uma nota seca $(2,5 \%) .^{3}$

Em seguida, concentramos a análise na identificação dos enquadramentos noticiosos ${ }^{4}$, descritos por Mauro Porto (2012) como sendo aqueles que envolvem os "padrões de apresentação, seleção e ênfase utilizados por jornalistas para organizar seus relatos". Identificamos cinco tipos de enquadramentos prevalecentes: "episódico" (dedicado à cobertura de acontecimentos, fatos e agenda, neste caso privilegiando a divulgação da entrega do relatório final e os fatos por ele estimulados, sem se aprofundar em temáticas específicas); "punitivo" (referente à responsabilização e punição dos perpetradores de atos criminosos, ou seja, ao desejo de justiça), "conflitivo" (relativo ao caráter de embate entre forças políticas ou entre grupos de cidadãos, como, por exemplo, em conflitos de interesse entre as Forças Armadas e a CNV), "reconhecimento" (voltado à apresentação temática dos resultados dos trabalhos, à valorização da importância da comissão, lembrança de suas principais ações e enaltecimento do trabalho realizado) e "cobrança" (relacionado à apresentação das recomendações e atrelado ao questionamento ou à reivindicação de sua aplicação).

As discussões sobre a identificação de perpetradores (listados por nome pela CNV), a Lei de Anistia e a relação conflituosa entre Forças Armadas e comissão permearam $42 \%$ do material analisado, evidenciando que, somados, os aspectos "conflitivos" (28\%) e "punitivos" (19\%) se sobressaíram na cobertura. 
Um exemplo da utilização do enquadramento "punitivo" é a matéria do Estadão intitulada "Para ONU, Brasil precisa agora processar responsáveis pela tortura". Uma outra mostra dessa aplicação pode ser observada no seguinte trecho de notícia veiculada pelo portal G1:

A Terceira Turma do Superior Tribunal de Justiça decidiu, por três votos a dois, que o coronel da reserva Carlos Alberto Brilhante Ustra pode ser responsabilizado por danos morais decorrentes de tortura durante a ditadura militar. Os ministros analisaram recurso do coronel contra decisão do Tribunal de Justiça de São Paulo, que o considerou responsável na área civil por danos a vítimas da ditadura. [...] Os ministros mantiveram interpretação do TJ-SP, segundo a qual a Lei da Anistia impede somente que uma pessoa seja julgada na esfera criminal, que apura responsabilidade sobre crimes cometidos (OLIVEIRA, 20145).

O uso do enquadramento "conflitivo" pode ser ilustrado pela matéria da Folha de S. Paulo "Relatório registra relação atribulada entre Comissão e as Forças Armadas", pela cobertura do portal G1 sobre a tentativa frustrada de grupos militares que almejavam suspender a divulgação do relatório ${ }^{6}$ e pela passagem a seguir, também divulgada pela Folha de S. Paulo:

O governo Dilma antevê uma reação pesada [por parte das Forças Armadas] ao relatório final da Comissão Nacional da Verdade. De acordo com auxiliares presidenciais, o documento conclusivo é "duríssimo" por, aos olhos da equipe palaciana, acusar de crimes presidentes e comandantes militares e relativizar o alcance da Lei da Anistia (NERY, 20147).

O jornal Folha de S. Paulo, aliás, foi o que mais garantiu espaço aos en- quadramentos de caráter "punitivo" e "conflitivo", conferindo esses enfoques a 13 matérias, o equivalente a mais de um terço do total de inserções que veiculou sobre o tema.

$\mathrm{O}$ aspecto de "reconhecimento" e valorização da importância da comissão foi perceptível em 21 notícias e reportagens (26\%) que, em geral, rememoraram o percurso da comissão e destacaram ações consideradas relevantes, mas também ressaltaram o fato de a presidente Dilma ter se emocionado durante a solenidade. Contudo, é preciso assinalar que outras narrativas semelhantes foram consideradas "episódicas", por centrarem-se apenas no fato em si - o choro da presidente e a descrição da solenidade - sem conferir destaque ao que a comissão representou e ao que recomendou ao Estado, como se pode observar no texto da Folha de S. Paulo, "Dilma recebe relatório da Comissão da Verdade e chora ao lembrar mortos", de 10 de dezembro:

A presidente Dilma Rousseff se emocionou e chorou durante a cerimônia de entrega do relatório final da Comissão Nacional da Verdade, realizada na manhã desta quarta-feira (10) no Palácio do Planalto. [...] "Vou repetir o que eu disse quando lançamos a Comissão Nacional da Verdade. Disse que o Brasil merecia a verdade, as novas gerações mereciam a verdade, e principalmente aqueles que perderam... [chora] Que continuam sofrendo como se eles morressem de novo a cada dia", disse a presidente, que foi longamente aplaudida neste momento. Dilma foi presa e torturada durante a ditadura. Após dois anos e sete meses de trabalho, a CNV concluiu o relatório, com cerca de 2.000 páginas. $\mathrm{O}$ documento foi entregue a Dilma pelo coordenador da CNV, Pedro Dallari. [...] A cerimônia foi acompanhada por ministros e demais autoridades do governo, além de integrantes de entidades ligadas aos direitos humanos, víti-
${ }^{5}$ Documento eletrônico não paginado.

${ }^{6}$ Ver mais em: <http:// g1.globo.com/politica/ noticia/2014/12/trf-1-nega -pedido-para-suspender-divulgacao-do-relatorio-sobreditadura.html>.

${ }^{7}$ Documento eletrônico não paginado. 
mas do período militar e familiares dos que já morreram (HAUBERT, MAGALHÃES, 2014 $)$.

No total, $17 \%$ do material foi en-

${ }^{8}$ Documento eletrônico não paginado.

${ }^{9}$ Documento eletrônico não paginado.

${ }^{10}$ Documento eletrônico não paginado.

${ }^{11}$ Documento eletrônico não paginado. quadrado de forma "episódica", o que refuta uma das hipóteses levantadas, segundo a qual esse tipo de enquadramento prevaleceria. Isso indica que, ao privilegiar outros tipos de enfoque, a imprensa brasileira valorizou o encerramento dos trabalhos da CNV, concedendo espaço além da corriqueira descrição do ato de entrega do relatório, tendo se voltado para aspectos mais relevantes. Entretanto, quando se observa a quantidade de material de caráter "conflitivo" e "punitivo", torna-se nítido que os conteúdos analisados privilegiaram, de algum modo, a espetacularização e o aspecto de embate entre forças políticas - valoresnotícia por natureza -, comprovando a segunda hipótese (de que a cobertura valorizaria o viés polêmico) e demonstrando assim o terreno de disputas e contradições que permeou as atividades do colegiado.

Já o "reconhecimento" dos trabalhos da CNV foi observado nas narrativas que buscaram destacar o histórico da comissão, os avanços por ela produzidos ou a voz de especialistas e militantes ao ressaltarem esse aspecto. No dia 12 de dezembro, por exemplo, a matéria "Comissão admite vítimas que Estado negava até então", veiculada pela Folha de S. Paulo, atribuiu à comissão a responsabilidade por ampliar o número de pessoas reconhecidamente vitimadas pela violência ditatorial. "O reconhecimento formal [pela comissão] de que o governo teve participação na morte ou no desaparecimento [de vítimas da ditadura], possibilita que familiares entrem com pedido de indenização contra o Estado" (ARAGÃO, AZEVEDO, 2014 ${ }^{9}$ ). Também $O$ Globo, em sua edição de 10 de dezembro, realçou a diferença feita pelo trabalho de resgate da memória autoritária:

A Comissão dá ainda um passo à frente ao responsabilizar o Estado por oito suicídios cometidos por ex-presos políticos. Alguns se mataram no exílio, outros no período democrático. $\mathrm{Na}$ interpretação dos comissionados, as mortes foram provocadas pelas torturas e violências sofridas na época da ditadura. Para as vítimas, teria sido penoso demais viver carregando consigo aquelas lembranças. O relatório tenta transformar essas lembranças pessoais tão doloridas em memória coletiva do país (SANCHES, $\left.2014^{10}\right)$.

Apesar destas incidências de enquadramento pelo enfoque de "reconhecimento e valorização", parte da cobertura revelou-se descrente em relação às consequências que o relatório poderia provocar, chegando mesmo a duvidar da sobriedade com que as atividades foram conduzidas, como no editorial do Estadão, "O trabalho de uma comissão", de 11 de dezembro.

Se a pretensão da Comissão da Verdade era reproduzir os fatos ocorridos durante o regime militar "em sua plenitude, sem ocultamentos", como disse a presidente Dilma Rousseff ao instalá-la, há dois anos e sete meses, esse objetivo não foi atingido. Mas que ninguém se surpreenda, pois estava claro desde o princípio que todo esse processo, cujo resultado é o relatório ora entregue pela comissão, tinha o objetivo de reescrever a história daquele período conforme uma narrativa que não só ignora os crimes da esquerda armada, como a transforma em mártir da democracia - embora agisse sob inspiração (e em alguns casos com financiamento e treinamento) de ditaduras comunistas (ESTADÃO, $\left.2014^{11}\right)$.

O fato de as Forças Armadas não terem reconhecido a própria atuação durante a ditadura nem terem se pronunciado oficialmente sobre as conclusões e 
recomendações da CNV pode ser considerado um ponto que, por ter dificultado os trabalhos de investigação, contribuiu para a valorização do aspecto conflitivo.

Diante do espaço conferido a tais enquadramentos, a abordagem sobre a aplicação das recomendações (enquadramento "cobrança") ficou em segundo plano, representando $10 \%$ do total. Duas das oito narrativas identificadas que podem servir de exemplo têm vieses distintos. Enquanto matéria do Estadão pode ser considerada pessimista ao afirmar que "o futuro dos quase três anos de trabalho da Comissão Nacional da Verdade ainda é incerto" ${ }^{12}$, por não haver garantias legais para que as recomendações sejam adotadas, em sua coluna no jornal Folha de S. Paulo, Bernardo de Mello Franco tocou em um ponto-chave de forma mais positiva:

O encerramento dos trabalhos da Comissão Nacional da Verdade escreve uma página importante na história do Brasil. Com quase três décadas de atraso, o Estado reconhece oficialmente, nesta quarta (10), os crimes praticados em seu nome durante a ditadura militar. Agora começa uma nova etapa, na qual o país terá que decidir o que fará com as conclusões do relatório. Há duas opções: tratar o documento como um registro histórico, a ser guardado nas bibliotecas, ou usá-lo como ponto de partida para o próximo passo. A comissão escolheu a segunda alternativa por cinco votos a um, como o "Painel" antecipou em novembro. Vai defender a responsabilização criminal de quem torturou e matou presos políticos [...] (MELLO FRANCO, 2014 ${ }^{13}$ ).

Ao que tudo indica, a comissão escolheu tal caminho, mas o governo brasileiro (ao menos até aqui) não. Os dois conteúdos mencionados acima destacam as dificuldades, contudo, enquanto o Estadão faz a crítica centrada na $\mathrm{CNV}$ e na arena política em que está inserida, a co- luna de Mello Franco pontua que "a nova etapa” envolvida no prosseguimento ou não das recomendações depende do país: ou seja, do governo e da sociedade.

\section{Conclusões: o desejável e o possível}

Chega-se à conclusão de que as proposições da CNV podem se transformar em letra morta se não forem amplamente divulgadas, defendidas por setores sociais e incorporadas por projetos políticos. Diferentemente da forma como a comissão foi instituída - em evento que contou com a presença da então presidente Dilma Rousseff e quatro ex-presidentes (José Sarney, Fernando Collor de Mello, Fernando Henrique Cardoso e Luís Inácio Lula da Silva) em ato inédito, articulado e com representação de autoridades, inclusive militares -, a solenidade de encerramento dos trabalhos da CNV transpareceu menos impacto. No Palácio do Planalto ${ }^{14}$, em ato da Presidência restrito a poucos ministros, convidados, imprensa e $\mathrm{CNV}$, ficou claro que o governo não garantiria o apoio político necessário às ressignificações almejadas. Ainda que a divulgação do relatório final tenha tido grande repercussão midiática, faltou vontade e condição política para transformá-lo em uma ação duradoura. Até o momento, as principais recomendações não foram cumpridas.

Uma das hipóteses que se poderia cogitar em estudos futuros é a de que a fragilidade política da presidente recém-reeleita naquele momento se refletiria em ambiente não propício para que algumas bandeiras polêmicas (como a revisão da Lei de Anistia) fossem defendidas. $\mathrm{Na}$ impossibilidade de testar tal proposição neste trabalho, o que tentou-se verificar foi como o jornalismo mainstream enquadrou o momento final da Comissão Nacional da Verdade. Paralelamente, foi desenvolvida abordagem pormenorizada das conclusões e recomendações do relatório final, tomandose por base reflexões teóricas advindas dos estudos sobre memória.

Tais estudos demonstram que grandes traumas históricos, envolvendo
${ }^{12}$ Disponível em: <http:// politica.estadao.com.br/ noticias/geral,efeito-praticode-recomendacoes-e-incerto -imp-,1605251>. Acesso em 10 jan. 2016.

${ }^{13}$ Documento eletrônico não paginado.

${ }^{14}$ Além da solenidade no Palácio do Planalto, a CNV realizou ato público com participação de militantes dos direitos humanos e movimentos sociais na sede da Ordem dos Advogados do Brasil (OAB) em Brasília. 
${ }^{15}$ Repetição não propriamente da lembrança, mas de atos derivados da memória inconsciente de um evento traumático. violações de direitos humanos em diversas partes do mundo, serviram e ainda servem de pano de fundo para as mais variadas análises sobre manifestações culturais. No espaço midiático, por força de suas especificidades, narrativas sobre experiências traumáticas, quando usadas de forma sensacionalista ou exploradas massivamente com exclusiva finalidade mercadológica, não raro traduzem-se naquilo que Ricoeur nomeia "excesso de memória" ou expressam algo semelhante à "compulsão de repetição" freudiana. Tal ímpeto compulsivo configura-se como reação sintomática ${ }^{15}$ a um recalque.

As proposições interpostas pelo relatório da Comissão Nacional da Verdade, em particular suas conclusões e recomendações aqui postas em tela, têm o efeito de um contradiscurso que não apenas denuncia o cunho repetitivo e superficialmente excessivo, definidor de boa parte das representações midiaticamente veiculadas sobre a ditadura militar brasileira, mas sobretudo têm o potencial de propor alternativas para a narração e expressão deste contexto.

$\mathrm{Na}$ contramão do esvaziamento de sentido resultante da mercadorização e da reificação de noções acerca do passado ditatorial posto em circulação por parcela significativa da mídia nacional, as (res)significações do regime militar discricionário oferecidas pela Comissão Nacional da Verdade ao debate público, sobretudo por meio de sua veiculação midiática, representam uma vivaz contribuição ao enriquecimento da memória e à elaboração de esquecimentos acerca de experiências históricas traumáticas. Sem ocultar as dificuldades envolvidas no processo, a CNV convida ao enfrentamento do dilema inerente à capacidade de lembrar e esquecer circunstâncias das quais, de modo algum, se pode escapar.

A análise empírica da repercussão do relatório nos principais meios de comunicação noticiosos do país permite uma dupla interpretação. De um lado, é notório o reconhecimento dos grupos hegemônicos na mídia brasileira de que, considerados os critérios de noticiabilidade e as pressões de grupos engajados na causa, há "interesse social" nos resultados apresentados pela CNV, o que se traduz na expressividade do número de inserções sobre o assunto nos dias subsequentes à entrega do relatório. Esta constatação confirma a primeira hipótese testada. Observa-se, por outro lado, um evidente desequilíbrio na distribuição deste destaque estritamente numérico (uma vez que o levantamento realizado não considerou aspectos como o espaço ou o tempo ocupado por cada unidade noticiosa), quando se compara a quantidade de inserções por veículo. A Folha de S. Paulo, por exemplo, publicou três vezes mais matérias (38) acerca da conclusão dos trabalhos da CNV do que o Estadão (12), enquanto no telejornal de maior audiência do Brasil, o Jornal Nacional, foi registrada uma única referência ao tema no período avaliado.

A segunda hipótese, a de que a cobertura destacou os aspectos mais polêmicos do relatório, também foi corroborada, pois, no que diz respeito aos enquadramentos, a cobertura evidenciou a feição controvertida do assunto presente no enfoque conflitivo-punitivo. Já a terceira hipótese - a de que o enquadramento episódico seria privilegiado, não havendo grande investimento no aprofundamento das discussões acerca do impacto político e social do relatório foi parcialmente comprovada. Ainda que tenha sido identificada quantidade significativa do aspecto episódico, de cunho mais superficial, a contagem numérica não foi suficientemente expressiva para patentear a prevalência do enquadramento "episódico". Por esta razão, a primeira parte da proposição hipotética foi refutada. De outro modo, os artigos voltados ao enfoque de "reconhecimento" e "cobrança" revelaram-se notórios em quantidade, mas não se mostraram satisfatoriamente aprofundados a ponto de promoverem amplas discussões acerca do impacto político e social do documento, ratificando a segunda parte da última hipótese examinada. 
Se os enquadramentos "punitivo" e "conflitivo" forem considerados separadamente, os resultados quantitativos demonstram que a cobertura aparenta ser equilibrada, visto que, entre os enfoques identificados, a distribuição ocorre do seguinte modo: "conflitivo" (28\%), "reconhecimento" (26\%), "punitivo" (19\%), "episódico" (17\%) e de "cobrança" (10\%). Contudo, a quantidade menor desse último enquadramento demonstra que o caráter questionador e reflexivo do jornalismo - que permitiria avaliar como as investigações foram conduzidas, checar os próximos passos, bem como reivindicar a aplicação das recomendações - ocupou lugar secundário em relação às demais formas de se enfocar o assunto. Ainda assim, o fato de o documento conclusivo da comissão ter suscitado abordagem jornalística que enfatiza o sentido polêmico e divergente das memórias relativas ao passado ditatorial - quando comparado ao silêncio e ao pseudoconsenso em torno do assunto outrora predominantes - pode ser computado na conta de um avanço, ainda que relativo, tendo-se em vista que um possível aprofundamento da cobertura foi evitado.

\section{Referências}

ARAGÃO, Alexandre, AZEVEDO, Rayanne. Comissão admite vítimas que Estado negava até então. Folha de S. Paulo, 12 dez. 2014. Disponível em: http://www1. folha.uol.com.br/poder/2014/12/1561303-comissao-admite-vitimas-que-estado-negava-ate-entao.shtml>. Acesso em: 25 ago. 2016.

BERGSON, Henri. Memória e vida: textos escolhidos por Gilles Deleuze. São Paulo: Martins Fontes, 2006.

CNV. Disponível em: <http://www.cnv.gov.br>. Acesso em: 1 set. 2012.

D'ANGELO, Paul; KUYPERS, Jim A. (ed.). Doing news framing analysis: empirical and theoretical perspectives. New York: Routledge, 2010.

ENTMAN, Robert. Framing: Toward Clarification of a Fractured Paradigm. In: Journal of Communication, 43(4), pp. 51-58, 1993. Disponível em: <http://www. unc.edu/ fbaum/teaching/POLI891_Sp11/articles/J-Communication-1993-Entman.pdf $>$. Acesso em: 3 fev. 2012.

FREEMAN, Mark. Truth Commissions and procedural fairness. New York: Cambridge University Press, 2006.

FREUD, Sigmund. Luto e melancholia. In: . Obras completas, vol. XIV. Tradução dirigida por Jayme Salomão. Rio de Janeiro: Imago, 1996. p. 245-266.

GITLIN, Todd. The whole world is watching: mass media in the making and unmaking of the new left. Berkeley: University of California Press, 1980.

HALBWACHS, Maurice. A memória coletiva. 2ed. São Paulo: Centauro, 2006. 
Comissão da Verdade e chora ao lembrar mortos. Folha de S. Paulo, 10 dez. 2014. Disponível em: <http://www1.folha.uol.com.br/poder/2014/12/1560238-dilmachora-ao-falar-sobre-ditadura.shtml>. Acesso em: 25 ago. 2016.

HAYNER, Priscilla B. Unspeakable truths: Transitional Justice and the challenge of truth commissions. 2ed. New York: Routledge, 2011.

HUYSSEN, Andreas. Seduzidos pela memória: arquitetura, monumentos, mídia. Rio de Janeiro: Aeroplano, 2000.

Culturas do passado-presente: modernismos, artes visuais, políticas da memória. Rio de Janeiro: Contraponto: Museu de Arte do Rio, 2014.

LE GOFF, Jacques. História e memória. Campinas: Editora da Unicamp, 1990.

LORAUX, Nicole. La ciudad dividida: el olvido de la memoria de Atenas. Buenos Aires: Katz, 2008.

MELLO FRANCO, Bernardo. O próximo passo. Folha de S. Paulo, 10 dez. 2014. Disponível em: < http://www1.folha.uol.com.br/colunas/bernardomellofranco/2014/12/1560115-o-proximo-passo.shtml>. Acesso em 10 fev. 2016.

NERY, Natuza. Planalto espera reação de militares ao relatório final da Comissão da Verdade. Folha de S. Paulo, 10 dez. 2014. Disponível em: < http://www1. folha.uol.com.br/poder/2014/12/1560260-planalto-espera-reacao-de-militares-ao-relatorio-final-da-comissao-da-verdade.shtml>. Acesso em 10 fev. 2016.

NIETZSCHE, Friedrich. Segunda consideração intempestiva: da utilidade e desvantagem da história para a vida. Rio de Janeiro: Relume Dumará, 2003.

Genealogia da moral: uma polêmica. Trad. Paulo César de Souza. São Paulo: Companhia das Letras, 2009.

OLIVEIRA, Mariana. STJ permite que Ustra responda por dano moral em casos de tortura. Disponível em: <http://g1.globo.com/politica/noticia/2014/12/stj-permite-que-ustra-responda-por-dano-moral-em-caso-de-tortura.html $>$. Acesso em 6 abril 2017.

O TRABALHO DE UMA COMISSÃO. Estadão, 11 dez. 2014. Disponível em $<$ http://opiniao.estadao.com.br/noticias/geral,o-trabalho-de-uma-comissaoimp-,1605315>. Acesso em 25 ago. 2016.

PORTO, Mauro. Enquadramentos da Mídia e Política. Anais da Anpocs, 2012. Disponível em: <http://www.anpocs.org/portal/index.php?option=com_docman\&task=doc_view\&gid=4400\&Itemid=217>. Acesso em: 15 jan. 2014.

RELATÓRIO DA CNV. Disponível em <http://www.cnv.gov.br/images/pdf/relatorio/volume_1_digital.pdf $>$. Acesso em 20 mar. 2016.

RICOEUR, Paul. A memória, a história, o esquecimento. Campinas-SP: Editora Unicamp, 2007.

SANCHES, Mariana. Relatório da Comissão da Verdade relata 30 tipos de tortura 
por militares. O Globo, 10 dez. 2014. Disponível em: <http://oglobo.globo.com/ brasil/relatorio-da-comissao-da-verdade-relata-30-tipos-de-tortura-por-militares-14789552>. Acesso em: 25 ago. 2016.

TUCHMAN, Gaye. Making News: A Study in the construction of reality. New York: The Free Press, 1978. 